\title{
Extinction of lean near-limit methane/air flames at elevated pressures under normal- and reduced-gravity
}

\author{
Hai Zhang ${ }^{\mathrm{a}, *}$, Rong Fan ${ }^{\mathrm{a}}$, Shuangfeng Wang ${ }^{\mathrm{b}}$, Xueqin Tian ${ }^{\mathrm{a}}$, Kao Xu ${ }^{\mathrm{a}}$, \\ Shixin Wan ${ }^{\mathrm{b}}$, Fokion N. Egolfopoulos ${ }^{\mathrm{c}}$ \\ ${ }^{a}$ Key Laboratory for Thermal Science and Power Engineering of Ministry Education, Department of Thermal Engineering, \\ Tsinghua University, Beijing 100084, China \\ ${ }^{\mathrm{b}}$ National Microgravity Laboratory, Institute of Mechanics, Chinese Academy of Science, Beijing 100080, China \\ ${ }^{\mathrm{c}}$ Department of Aerospace and Mechanical Engineering, University of Southern California, Los Angeles, \\ CA 90089-1453, USA
}

Available online 6 August 2010

\begin{abstract}
The extinction limits of lean, near-limit, counterflowing, $\mathrm{CH}_{4} /$ air twin premixed flames were studied experimentally at evaluated pressures and under normal- and micro-gravity conditions utilizing the $3.5 \mathrm{~s}$ drop tower of the National Microgravity Laboratory of China. The results showed that under micro-gravity conditions the natural convection is minimized and the flames become more planar and symmetric compared to normal gravity. In both normal- and micro-gravity experiments and for a given strain rate and fuel concentration, the flame luminosity was found to enhance as the pressure increases. On the other hand, at a given pressure, the flame luminosity was determined to weaken as the strain rate decreases. At a given strain rate, the fuel concentration at extinction was found to vary non-monotonically with pressure, namely it first increases and subsequently decreases with pressure. The limit fuel concentration peaks around 3 and $4 \mathrm{~atm}$ under normal- and micro-gravity, respectively. The extinction limits measured at micro-gravity were in good agreement with predictions obtained through detailed numerical simulations but they are notably lower compared to the data obtained under normal gravity. The simulations confirmed the non-monotonic variation of flammability limits with pressure, in agreement with previous studies. Sensitivity analysis showed that for pressures between one and $5 \mathrm{~atm}$, the near-limit flame response is dominated by the competition between the main branching, $\mathrm{H}+\mathrm{O}_{2} \rightarrow \mathrm{OH}+\mathrm{O}$, and the pressure sensitive termination, $\mathrm{H}+\mathrm{O}_{2}+\mathrm{M} \rightarrow \mathrm{HO}_{2}+\mathrm{M}$, reaction. However, for pressures greater than $5 \mathrm{~atm}$ it was determined that the $\mathrm{HO}_{2}$ kinetics result in further chain branching in a way that is analogous to the third explosion limit of $\mathrm{H}_{2} / \mathrm{O}_{2}$ mixtures.

(C) 2010 The Combustion Institute. Published by Elsevier Inc. All rights reserved.
\end{abstract}

Keywords: Flame extinction; Flammability limits; Premixed flames; Micro-gravity

* Corresponding author. Fax: +861062781743.

E-mail address: haizhang@tsinghua.edu.cn(H.Zhang).

\section{Introduction}

Studying the extinction of weakly strained, near-limit flames is of significance both from a practical and theoretical point of view. Additionally, such studies provide insight into the flamma- 
bility limit (FL) of a gaseous reacting mixture, a very important and frequently misunderstood and misinterpreted combustion phenomenon.

Theoretically, FL is defined as the concentration (equivalence ratio) limit $\phi_{\text {limit }}$ beyond which propagation is not possible for an one-dimensional, steady, planar, laminar, unstrained, and nearly adiabatic flame (e.g. [1-3]), hereafter referred to as the ideal one-dimensional flame (IODF). However, the experimental determination of $\phi_{\text {limit }}$ is complicated largely by two factors. First, it is not possible to reproduce the IODF model in the laboratory. Second, as $\phi_{\text {limit }}$ is approached experimentally, the burning rate is low enough so that under normal gravity (1-g) buoyancy-induced natural convection affects flame stability and masks the underlying mechanism that control the flame behavior close to extinction. Thus, experiments need to be conducted under micro-gravity or reduced-gravity $(\mu \mathrm{g})$ conditions (e.g. [4-7]).

Traditionally, FL's have been determined experimentally through the standard flame tube (e.g. $[8,9]$ ) and/or the spherical bomb (e.g. [6]). In both approaches, however, flame propagation is influenced by largely unquantified effects of heat and radical losses, unsteadiness, strain rate, and ignition energy "memory effect" that are external to the mixture. Subsequently, stagnation-type flames were proposed as means to determine FL's [10]. The technique involves determining the extinction strain rate, $K_{\text {ext }}$, by systematically varying the mixture's equivalence ratio, $\phi$, and the subsequent determination of $\phi_{\text {limit }}$ through linear extrapolation to $K_{\text {ext }}=0$.

In subsequent studies (e.g. [5,7,11-16]), major advances were made towards the better quantification and understanding of the mechanisms of FL's through experiments at normal and reduced-gravity as well as numerical simulations with detailed description of chemical kinetics, molecular transport, and thermal radiation. These studies have revealed for the first time a close agreement between the experimental and computed $\phi_{\text {limit }}$ 's. Additionally, the existence of FL's based on the IODF model has been confirmed and has been attributed to the synergistic effect of kinetic chain mechanism competition and radiative losses, both being intrinsic properties of a mixture.

In the vast majority of past studies, the effect of pressure on FL's has not been adequately addressed even though pressure can have a profound effect on both chain mechanisms and thermal radiation. Egolfopoulos et al. [17] determined $\phi_{\text {limit }}$ 's through a detailed numerical study for pressures, $p$, ranging from 1 to $50 \mathrm{~atm}$ and for unburned mixture temperatures, $T_{\mathrm{u}}$, ranging from 300 to $700 \mathrm{~K}$. The study revealed that for all $T_{\mathrm{u}}$ 's, $\phi_{\text {limit }}$ increases for $1 \leqslant p \leqslant 5 \mathrm{~atm}$ and decreases for $p>5 \mathrm{~atm}$. Additionally, it was determined that for low $p$ 's, the competition between the main branching
$\mathrm{H}+\mathrm{O}_{2} \rightarrow \mathrm{O}+\mathrm{OH}$

and main termination

$\mathrm{H}+\mathrm{O}_{2}+\mathrm{M} \rightarrow \mathrm{HO}_{2}+\mathrm{M}$

reactions are the dominant ones. As $p$ increases, however, it was shown that the kinetics of $\mathrm{HO}_{2}$, which is produced in excess quantities, become gradually more important and result in additional chain branching. While those computed results are of interest, there is no experimental evidence that supports the non-monotonic dependence of $\phi_{\text {limit }}$ on $p$, which would validate both the kinetic and radiation models and thus confirm the theoretical conclusions. Given the relevance of lean burning to $\mathrm{NO}_{x}$ emissions reduction in engines, the accurate knowledge of the lean FL's at pressures greater than atmospheric is of particular importance.

Based on the aforementioned considerations, the main goal of this investigation was to conduct an experimental and computational study of FL's at variable pressures, and assess the validity of the previous theoretical findings [17]. The experiments were performed for lean $\mathrm{CH}_{4} /$ air mixtures in a variable pressure, counterflow flame rig at $1-g$ as well as $\mu \mathrm{g}$ utilizing the drop tower at the National Microgravity Laboratory of China (NMLC) in Beijing. The experiments were modeled using detailed description of chemical kinetics, molecular transport, and thermal radiation and sensitivity analysis was implemented to provide insight into the kinetic mechanisms that control FL's.

\section{Experimental approach}

Fig. 1 depicts the schematic of the experimental configuration, mainly consisting of a two opposing burners, a pressure chamber, auto-control system, data acquisition, and image monitoring system, as well as gas supply and exhaust collection system. The overall experimental rig was designed to meet the specifications of the NMLC's drop tower. A standard capsule was used to enclose the burner and pressure chamber assembly as well as the attendant flow panel and electronics. During the experiments, the capsule was released from a platform located at an elevation of $83 \mathrm{~m}$, achieving thus $10^{-3}-10^{-4} \mathrm{~g}$ with an effective $\mu \mathrm{g}$ time of about $3.6 \mathrm{~s}$. For convenience, those experiments were still called micro-gravity $(\mu \mathrm{g})$ ones, though the gravity level was higher than $10^{-6} \mathrm{~g}$.

The pressure chamber is cylindrical with $250 \mathrm{~mm}$ internal diameter and $400 \mathrm{~mm}$ length, and it is made out of high-strength aluminum. The flames were monitored through an observation window on the chamber wall. The two opposing burners are mounted inside the pressure chamber and each burner is connected to a gas supply tube and a flow rectifier. The exit velocity profile from 


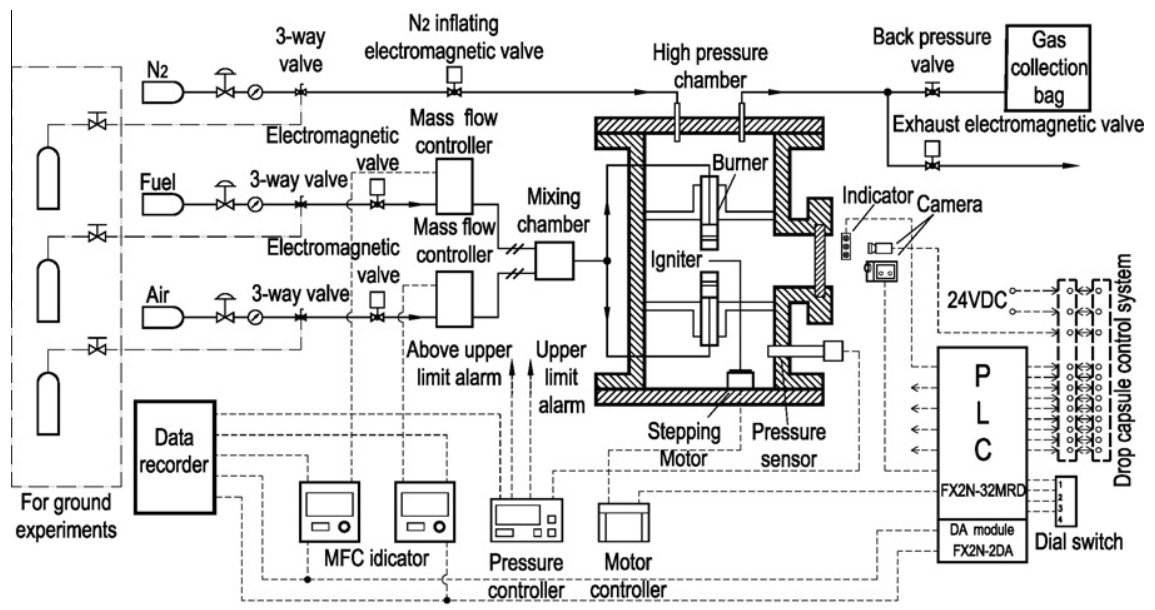

Fig. 1. Schematic of the experimental configuration.

each burner is top hat achieved through properly designed contoured nozzles with an exit diameter $D=14 \mathrm{~mm}$. A $4 \mathrm{~mm}$ diameter tube is used as the gas supply line and close to the burner exit the tube is expanded to a $10 \mathrm{~mm}$ diameter. Two sintered plates are installed to rectify the diffusing flow. The thickness of the plates is $1 \mathrm{~mm}$ to minimize flow resistance. The ignition system consists of a spark generator, a step electronic motor, and a spark holder is installed also in the chamber. The motor is remotely controlled and turns the spark holder in and out from the test section between the two nozzles.

The core device of the control system is a PLC controller with 17 input and 15 output channels. Transistor outputs are used to assure quick response of the ignition control. Five route signals are continuously acquired, including the preset flowrates of air and fuel, the flowrate of air and fuel fed back from the flowrate controller, and the chamber pressure. All signals are acquired at a $30 \mathrm{~Hz}$ frequency. Flame images are captured with a $640 \times 480$ resolution CCD camera at a $30 \mathrm{~Hz}$ frequency as well. Images of flame ignition and extinction are separately recorded with an additional CCD camera.

The chamber is allowed to fill from its top with high purity $\mathrm{N}_{2}$ prior to each $\mu \mathrm{g}$ experiment by utilizing a pressure control valve on the ground. The control valve is switched then to a line that connects a 1-1 aluminum tank onboard the rig and filled with high pressure $\mathrm{N}_{2}$ so that the chamber pressure is maintained constant during the entire test period. The chamber pressure is measured continuously and the signal is stored and transferred to the PLC controller so that the control valve could perform the necessary adjustments. The reactants, $\mathrm{CH}_{4}$ and air, are separately stored in individual 1-1 aluminum tanks and their flow rates are controlled with mass flow meters. The exhaust gases are collected in a gas collection bag that is evacuated at the beginning of each experiment.

The experiments at 1 -g were conducted using the same rig so that the data are consistent with those obtained at $\mu \mathrm{g}$. As $p$ increases, it is expected that near-limit flames are strongly affected by buoyancy at 1 -g and their extinction at lower strain rates are more sensitive to buoyancy than to thermal radiation [6].

Similar to the approach used by Maruta et al. [5], before the rig is released, twin flames are established at $\phi \approx 0.6$. When the chamber pressure is set to the desired value, $\phi$ is gradually reduced and the twin flames start to merge (e.g. [18]). When the distance between the two flames is about $5 \mathrm{~mm}$, a signal is sent to trigger the drop. At $\mu \mathrm{g}, \phi$ keeps decreasing so that the flames eventually extinguish. For a near-limit flame the characteristic time induced by buoyancy is about $10^{-2} \mathrm{~s}[6]$. The $\phi$ varying at a rate of $0.1 \mathrm{~s}^{-1}$. Thus, the overall process could be considered as a quasi-steady state. During the experiments, the total flow rate is kept nearly constant by keeping the air flow rate constant, which determines largely the nozzle exit velocity for fuel lean mixtures. The global strain rate, $K_{\text {global }}$, is defined as $K_{\text {global }} \equiv 2 U_{\text {exit }} / L$, where $U_{\text {exit }}$ is the nozzle exit velocity and $L$ the nozzle separation, which for all experiments was $L=14 \mathrm{~mm}$.

An important issue related to the $\phi$ reduction upon the release of the rig, is the time delay between the moment that the fuel flowrate is modified at the mixing location and the moment that this modification is sensed by the flame. Without proper calibration of this time delay, the equivalence ratio at extinction, $\phi_{\text {ext }}$, for a given $K_{\text {global }}$, cannot be determined accurately. In the study by Maruta et al. [5], the delay time was defined as the time from the moment that the flowrate controller was turned off to the moment that the flames extinguished. In 
the present studies, however, it was determined that the flowrate variation did not follow the abrupt change imposed by the flowrate controller. As shown in Fig. 2, when the flowrate is suddenly shut off, the measured flowrate gradually changes to zero, typically within a few seconds, and thereby the twin flames could potentially last for a while before extinction occurs. Therefore, in the present experiments, the delay time was defined as the time between the moment that the flowrate was modified by the controller to the moment that the flames starts moving towards the stagnation plane, indicative of the fuel composition modification at the flame location. Fig. 3 depicts typical results of delay time calibration at $1-\mathrm{g}$ at $p=2 \mathrm{~atm}$ as function of $U_{\text {exit }}$. It was determined also that the measured delay times agree well with calculated ones resulting from the division of the total volume of the gas line by the known volumetric flow rate.

During the experiments, the air flow rate of air streams was constant, while $\phi$ was changing within a time period. The $\phi$ was actually calculated based on the flow rate data acquired at the flowrate controllers. A LED indicator was turned ON at the moment (denoted as $t=0$ ) that the fuel flowrate reduction was triggered. From the video taken by a frequency fixed CCD camera, the elapsed time from $t=0$ to the moment of appearance of any image could be easily counted. Corrected by the constant delay time off-set, the temporal variation of $\phi$ at the flame front, including the $\phi_{\text {ext }}$, during each $\mu \mathrm{g}$ experiment could be determined based on the flowrate data. Fig. 4 depicts the determination of a specific $\phi_{\text {ext }}$ using the aforementioned approach. The location of the flame front at different elapsed times was determined by processing the CCD recorded images using MATLAB software.

\section{Numerical approach}

Using the PREMIX code $[19,20] \phi_{\text {limit }}$ 's onedimensional freely propagating flames were

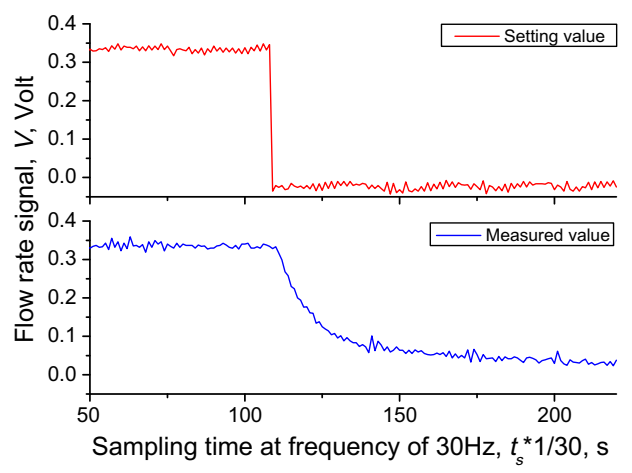

Fig. 2. Typical variations of the setting and measured signals of the flowrate controller.

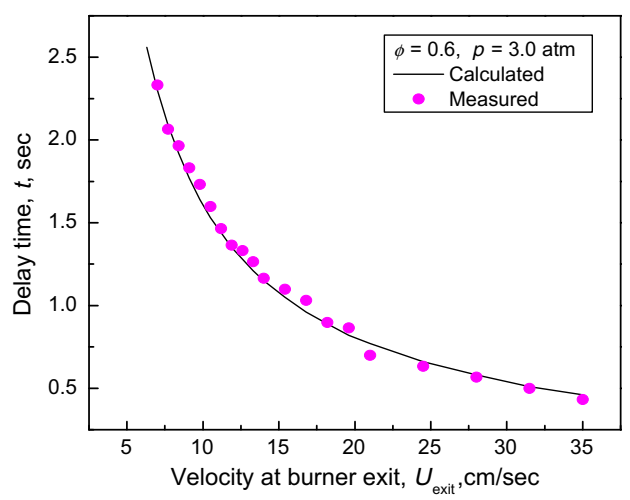

Fig. 3. Example of delay time calibration at normal gravity and $p=2$ atm.

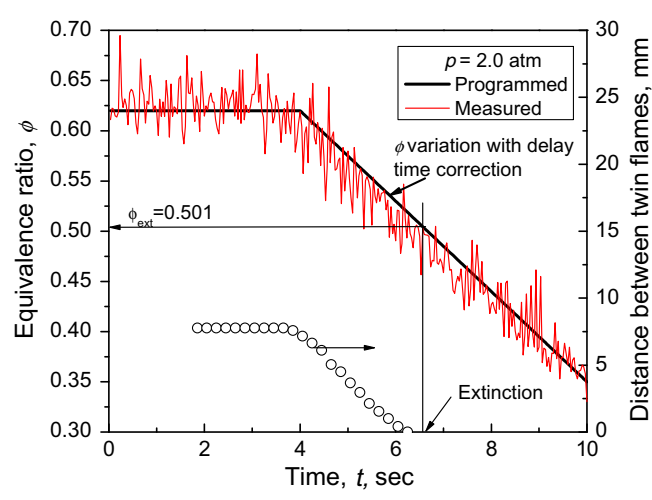

Fig. 4. Determination of the equivalence ratio utilizing the delay time calibration.

computed. The numerical determination of $K_{\text {ext }}$, corresponding to the $\mu \mathrm{g}$ experiments, was performed using a CHEMKIN based opposed-jet code originally developed by Kee and coworkers [21]. Both codes have been modified to account for thermal radiation of $\mathrm{CH}_{4}$, carbon monoxide (CO), carbon dioxide $\left(\mathrm{CO}_{2}\right)$, and water $\left(\mathrm{H}_{2} \mathrm{O}\right)$ in the optically thin limit (e.g. [7]) and are coupled with the Sandia CHEMKIN [22] and Transport [23] subroutine libraries. For small-scale fuel lean flames such radiation model is appropriate $[6,7]$.

Similar to previous studies [7,24,25], one-point continuation approach with a pre-determined temperature reduction at one-point within the computational domain was implemented in both codes in order to achieve solutions around turning points and determine thus $\phi_{\text {limit }}$ were with the PREMIX and $K_{\text {ext }}$ with the opposed-jet code.

In all simulations, the temperature boundary value at the burner exit was considered to be ambient, as the experimental times were rather short to allow for any notable heating of the burner nozzles. The GRI 3.0 model [26] was used to describe the oxidation kinetics of $\mathrm{CH}_{4}$ /air mixtures. 


\section{Results and discussion}

Experiments performed for $\phi=0.6$ and $1-\mathrm{g}$, revealed that the twin flames were asymmetric even though the flow conditions in each burner were identical, and that a distinct trough developed around the center of each flame. Furthermore, for $\phi<0.6$ the flames could not be stabilized at low strain rates.

In both $1-\mathrm{g}$ and $\mu \mathrm{g}$ experiments, it was determined that at a given strain rate, as $p$ increases from 1 to $5 \mathrm{~atm}$, the flame luminosity was enhanced, primarily due to the increase of mass burning intensity and the attendant increase of the molar concentration of light-emitting $\mathrm{CH}$ radicals. At the same time, the flame thickness, as determined by the luminous zone, was found to decrease as $p$ increased. For $p>3 \mathrm{~atm}$, the variation of flame thickness with $p$ became more gradual. For a given $p$ on the other hand, as the strain rate decreased the flame luminosity was found to decrease again due to the attendant reduction of the burning rate caused by the synergistic effects of stretch and the preferential diffusion for Le $<1$ mixtures (e.g. [18]). Fig. 5 depicts images of the flames during the entire time sequence of a $\mu \mathrm{g}$ experiment at $p=3 \mathrm{~atm}$. It can be seen that as the natural convection is minimized at the onset of $\mu \mathrm{g}$, the twin flames develop a notably more planar shape and they are rather symmetric across the stagnation plane. Additionally, as $\phi$ decreases under $\mu \mathrm{g}$, the twin flames move towards the stagnation plane and eventually extinguish upon further reduction of $\phi$.

The variation of the experimental $\phi_{\text {ext }}$ with $p$ for $K_{\text {global }}=14$ and $20 \mathrm{~s}^{-1}$ is shown in Fig. 6 for both 1$\mathrm{g}$ and $\mu \mathrm{g}$ conditions, along with the results of the detailed numerical simulations. It can be seen that the qualitative variations of the experimental $\phi_{\text {ext }}$ with $p$ at $\mu$ g and 1-g agree with each other as well as with the computed one. More specifically, the experiments confirm that $\phi_{\text {ext }}$ varies non-monotonically with $p$ in the $1 \leqslant p \leqslant 5$ atm range considered herein and that a maximum $\phi_{\text {ext }}$ is realized at $p \approx 3$ atm at 1 -g and at $p \approx 4$ atm at $\mu$ g and the simulations. The discrepancy between the $1-\mathrm{g}$ and $\mu \mathrm{g}$ data can be attributed to buoyancy that induces instabilities especially at the outer edge of the flame where the strain rate is notably reduced and that tends to induce extinction at higher $\phi$ 's. Apparently, this is not the case in the $\mu \mathrm{g}$ experiments whose boundary conditions are represented properly by the numerical simulations. The close agreement between the $\mu \mathrm{g}$ data and the computed ones suggests that the GRI 3.0 is reliable in predicting the extinction behavior of near-limit $\mathrm{CH}_{4}$ /air mixtures at normal and elevated pressures. The minor discrepancies could be attributed to experimental uncertainties.

In order to investigate further the mechanisms that result in the non-monotonic response of $\phi_{\text {ext }}$ to $p$, freely propagating $\mathrm{CH}_{4}$ /air flames were computed to determine the variation of $\phi_{\text {limit }}$ with $p$. In agreement with previous simulation results [17], $\phi_{\text {limit }}$ increases first with $p$ and then decreases with the maximum $\phi_{\text {limit }}$ value realized at $p \approx 5 \mathrm{~atm}$ as shown in Fig. 7. It is of interest to note that the trend of the $\phi_{\text {limit }}$ vs. $p$ variation is similar to that of $\phi_{\text {ext }}$ vs. $p$ for weakly strained flames and this constitutes the first experimental validation of the previous theoretical findings [17]. In addition, it can be seen that the pressure effect is more profound for low $p$ 's.

The initial increase of $\phi_{\text {limit }}$ with $p$ is caused by the competition between (R1) and (R2) for $\mathrm{H}$ radicals as $p$ increases (e.g. $[2,3,18]$ ), similarly to the second explosion limit of $\mathrm{H}_{2} / \mathrm{O}_{2}$ mixtures. Egolfopoulos et al. [17] have attributed the subsequent reduction of $\phi_{\text {limit }}$ with $p$ to the excessive production of $\mathrm{HO}_{2}$ that eventually results in additional branching channels in a way that is analogous to the third explosion limit of $\mathrm{H}_{2} / \mathrm{O}_{2}$ mixtures.

This point was confirmed further by performing sensitivity analysis of the mass burning rate on kinetics at $p=0.5,1,5,10$, and $40 \mathrm{~atm}$, and the results are shown on Fig. 8 for stoichiometric and limit flames.

The results show that for stoichiometric flames, as $p$ increases from 1 to $10 \mathrm{~atm},(\mathrm{R} 1)$ exhibits notably the most positive sensitivity while the $\mathrm{H}$ termination reaction

$\mathrm{H}+\mathrm{CH}_{3}+\mathrm{M} \rightarrow \mathrm{CH}_{4}+\mathrm{M}$

exhibits the highest negative sensitivity at all pressures.

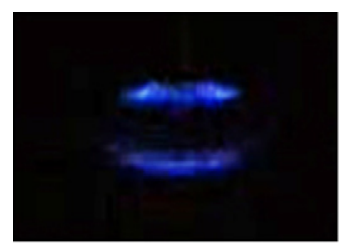

a

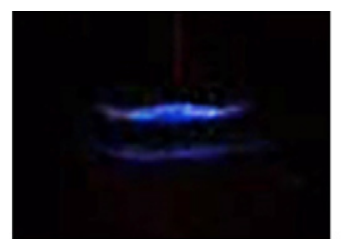

b

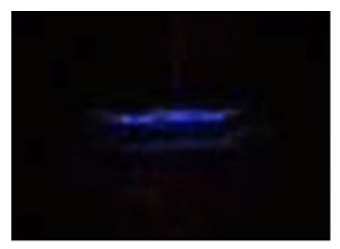

C

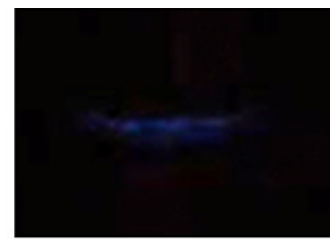

d

Fig. 5. Images of counterflowing premixed flames during micro-gravity experiments at $p=3$ atm. (a) Right after ignition at normal gravity; (b) Right before drop at normal gravity (c); During stable burning at micro-gravity; (d) Right before extinction at micro-gravity. 

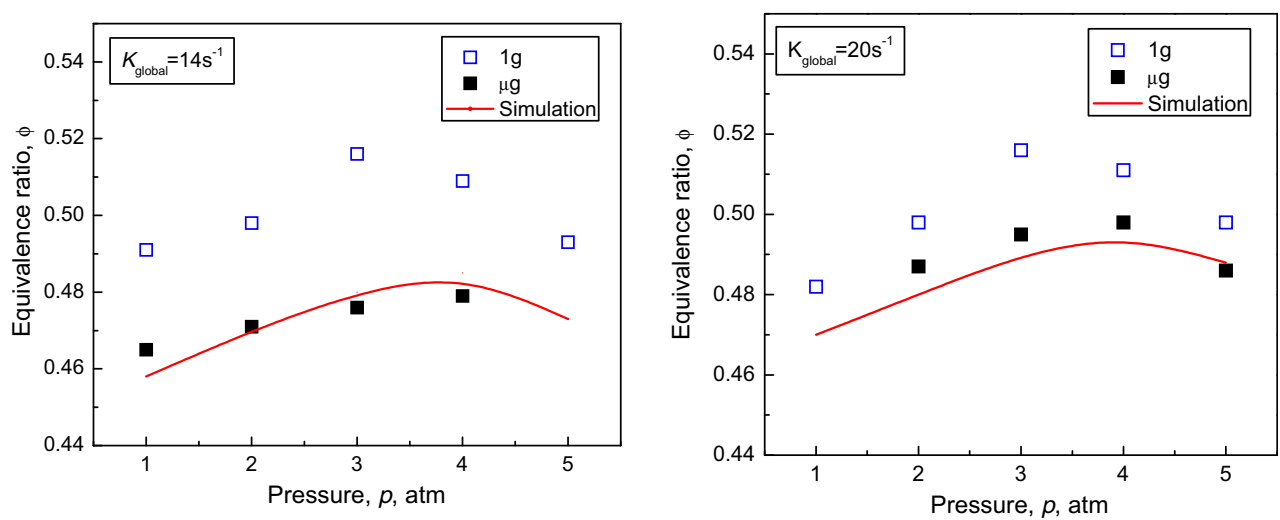

Fig. 6. Variation of the equivalence ratio at extinction with pressure at normal- and micro-gravity for global strain rate $K_{\text {global }}=14$ (left) and $20 \mathrm{~s}^{-1}$ (right). (Symbols: experimental data; Lines: numerical simulations).

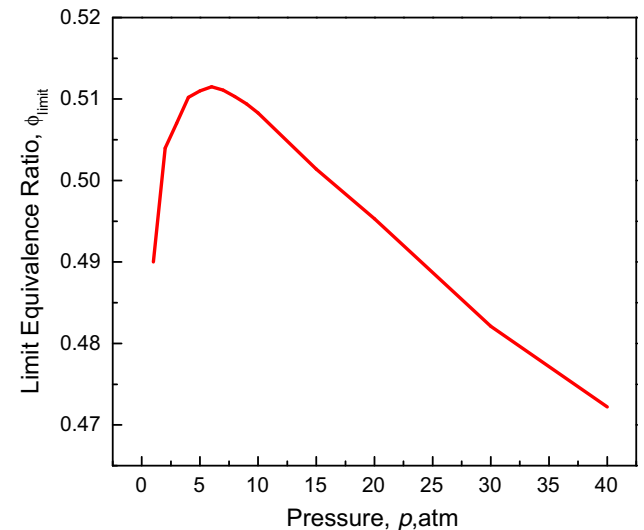

Fig. 7. Variation of the flammability limit with pressure computed for freely propagating $\mathrm{CH}_{4}$ /air flames at $T_{u}=298 \mathrm{~K}$.

For near-limit flames though, while (R1) exhibits in general the highest positive sensitivity, for $p>5 \mathrm{~atm}$, the $\mathrm{HO}_{2}$ concentration increases and its reactions with $\mathrm{CH}_{3}$ and $\mathrm{CH}_{2} \mathrm{O}$

$$
\begin{aligned}
& \mathrm{HO}_{2}+\mathrm{CH}_{3} \rightarrow \mathrm{OH}+\mathrm{CH}_{3} \mathrm{O} \\
& \mathrm{HO}_{2}+\mathrm{CH}_{2} \mathrm{O} \rightarrow \mathrm{HCO}+\mathrm{H}_{2} \mathrm{O}_{2}
\end{aligned}
$$

exhibit notable and eventual higher sensitivity compared to (R1). In methane flames, $\mathrm{CH}_{3}$ is readily produced directly from the fuel and its oxidation under fuel lean conditions results in $\mathrm{CH}_{2} \mathrm{O}$. As $p$ increases, the rates of (R4) and (R5) increase resulting in the production of $\mathrm{OH}$ and $\mathrm{H}$ via (R4) and

$$
\begin{aligned}
& \mathrm{H}_{2} \mathrm{O}_{2}+\mathrm{M} \rightarrow \mathrm{OH}+\mathrm{OH}+\mathrm{M} \\
& \mathrm{CH}_{3} \mathrm{O}+\mathrm{M} \rightarrow \mathrm{CH}_{2} \mathrm{O}+\mathrm{H}+\mathrm{M}
\end{aligned}
$$

$\mathrm{CH}_{2} \mathrm{O}$ that is produced by (R7) results in $\mathrm{HCO}$ whose decomposition

$$
\mathrm{HCO}+\mathrm{M} \rightarrow \mathrm{CO}+\mathrm{H}+\mathrm{M} \text {. }
$$

is an additional source of $\mathrm{H}$. The role of the fuel itself in this branching scheme is apparent by the large positive sensitivity that the $\mathrm{H}$ abstraction reaction

$\mathrm{OH}+\mathrm{CH}_{4} \rightarrow \mathrm{CH}_{3}+\mathrm{H}_{2} \mathrm{O}$

exhibits as $p$ increases stemming from the fact that it is the main source of $\mathrm{CH}_{3}$ that is used by (R4).

Additionally, for near-limit flames there is a notable change of the importance of the reactions that exhibit the highest negative sensitivities. More specifically, while at $p=1 \mathrm{~atm}$ the pressure-dependent three-body (R2) exhibits the highest negative sensitivity on flame propagation, this is not the case at $p=5$ and $10 \mathrm{~atm}$ at which the pressure-neutral two-body

$\mathrm{OH}+\mathrm{HO}_{2} \rightarrow \mathrm{O}_{2}+\mathrm{H}_{2} \mathrm{O}$

reaction appears to have the most negative effect as it eliminates $\mathrm{OH}$ that is produced by the (R4)-(R6) sequence.

Thus, as $p$ increases above about $5 \mathrm{~atm} \phi_{\text {limit }}$ decreases for two reasons. First, the excess production of $\mathrm{HO}_{2}$ results in chain branching in a way that is analogous to the third explosion limit of $\mathrm{H}_{2} / \mathrm{O}_{2}$ mixtures. Second, the chain termination pressure-dependent (R2) results in $\mathrm{HO}_{2}$ that leads to branching while the pressure-neutral two-body (R10) becomes the main termination reaction.

\section{Concluding remarks}

The present experimental results revealed that both gravity and pressure have a notable effect on the extinction limits of near-limit flames. At normal gravity, buoyancy induces instabilities for weakly burning flames that tend to facilitate extinction. At micro-gravity, the flames are notably more planar and stable compared to normal 

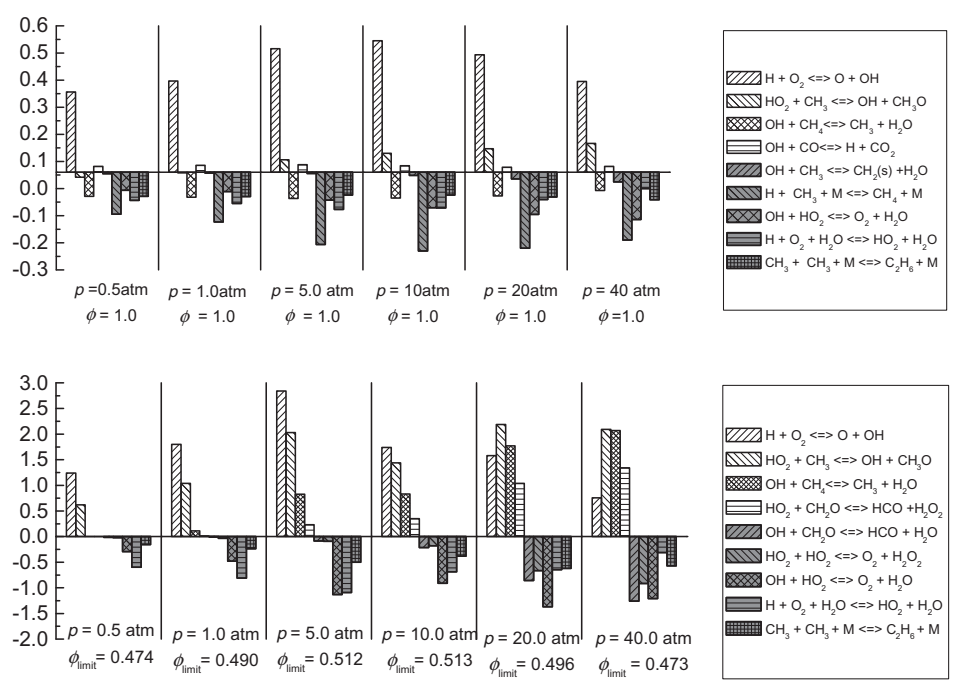

Fig. 8. Logarithmic sensitivity coefficients of the mass burning rate on kinetics for both stoichiometric and limits flames at $p=0.5,1,5,10,20$, and $10 \mathrm{~atm}$ and $T_{u}=298 \mathrm{~K}$.

gravity, and extinction was found to occur at lower equivalence ratios compared to normal gravity for a given strain rate. At both normaland micro-gravity, the experiments showed that the dependence of the equivalence ratio at extinction for a given strain rate first increases and subsequently decreases with pressure. The predicted extinction limits through detailed numerical simulations were found to be in close agreement with the experimental data obtained under micro-gravity conditions.

Simulations performed for freely propagating flames, revealed that the predicted dependence on the fundamental flammability limits on pressure is very similar to that of the extinction limits of weakly strained flames. Sensitivity analysis revealed that at pressures less than $5 \mathrm{~atm}$, the competition between the main branching $\left(\mathrm{H}+\mathrm{O}_{2} \rightarrow\right.$ $\mathrm{O}+\mathrm{OH})$ and termination $\left(\mathrm{H}+\mathrm{O}_{2}+\mathrm{M} \rightarrow \mathrm{HO}_{2}\right.$ $+\mathrm{M})$ reactions control the extinction behavior of weakly strained flames as well as the flammability limits, similarly to the second explosion limit of $\mathrm{H}_{2} / \mathrm{O}_{2}$ mixtures. As the pressure increases above fine atmospheres, the $\mathrm{HO}_{2}$ kinetics result eventually to additional branching in a way that is analogous to the third explosion limit of $\mathrm{H}_{2} / \mathrm{O}_{2}$ mixtures.

While the theoretical results of this study are in agreement with findings reported in the recent literature, it is the first experimental evidence that a non-monotonic dependence of the extinction limits on pressure exists.

\section{Acknowledgements}

The work at Tsinghua University was supported by NFSC (Grant No. 50576041). The support and cooperation provided by NMLC are highly appreciated. The work at the University of Southern California was supported as part of the CEFRC, an Energy Frontier Research Center funded by the U.S. Department of Energy, Office of Science, Office of Basic Energy Sciences under Award Number DE-SC0001198.

\section{References}

[1] F.A. Williams, Combustion Theory, second ed., Benjamin, Cummings, Menlo Park, CA, 1985.

[2] C.K. Law, Combustion Physics [M], Cambridge Press, 2006.

[3] C.K. Law, F.N. Egolfopoulos, Proc. Combust. Inst. 24 (1992) 137-144.

[4] P.D. Ronney, H.Y. Wachman, Combust. Flame 62 (1985) 107-119.

[5] K. Maruta, M. Yoshida, Y. Ju, T. Niioka, Proc. Combust. Inst. 26 (1996) 1283-1289.

[6] P.D. Ronney, Proc. Combust. Inst. 23 (1998) 24852506.

[7] H. Zhang, F.N. Egolfopoulos, Proc. Combust. Inst. 28 (2000) 1875-1882.

[8] H.F. Coward, G.W. Jones, Bureau Mines Bull. 503 (1952).

[9] R.A. Strehlow, K.A. Noe, B.L. Wherley, Proc. Combust. Inst. 21 (1986) 1899-1908.

[10] C.K. Law, D.L. Zhu, G. Yu, Proc. Combust. Inst. 21 (1986) 1419-1426.

[11] C.K. Law, F.N. Egolfopoulos, Proc. Combust. Inst. 23 (1990) 413-421.

[12] K.N. Lakshmisha, P.J. Paul, H.S. Mukunda, Proc. Combust. Inst. 23 (1990) 433-440.

[13] G. Dixon-Lewis, Proc. Combust. Inst. 25 (1994) 1325-1332.

[14] F.N. Egolfopoulos, Proc. Combust. Inst. 25 (1994) 1375-1381. 
[15] C.J. Sung, C.K. Law, Proc. Combust. Inst. 26 (1996) 865-873.

[16] H.S. Guo, G.J. Smallwood, F.S. Liu, Y.G. Ju, O.L. Gulder, Proc. Combust. Inst. 30 (2005) 303-311.

[17] F.N. Egolfopoulos, A.T. Holley, C.K. Law, Proc. Combust. Inst. 31 (2007) 3015-3022.

[18] C.K. Law, Proc. Combust. Inst. 22 (1989) 1381-1402.

[19] F.N. Egolfopoulos, Proc. Combust. Inst. 25 (1994) $1365-1373$.

[20] F.N. Egolfopoulos, C.S. Campbell, J. Fluid Mech. 318 (1996) 1-27.

[21] R.J. Kee, J.F. Grcar, M.D. Smooke, J.A. Miller, Sandia Report SAND85-8240, 1985.
[22] R.J. Kee, F.M.Rupley, J.A.Miller, Sandia Report SAND89-8009, 1989.

[23] R.J.Kee, J.Warnatz, J.A.Miller, Sandia Report SAND83-8209, 1983.

[24] M. Nishioka, C.K. Law, T. Takeno, Combust. Flame 104 (1996) 328-342.

[25] J. Ruan, M.H. Kobayashi, T. Niioka, Combust. Flame 124 (2001) 225-230.

[26] G.P. Smith, D.M. Golden, M. Frenklach, N.W. Moriarty, B. Eiteneer, M. Goldenberg, C.T. Bowman, R.K. Hanson, S. Song, W.C. Gardiner Jr., V. Lissianski, Z. Qin, GRI-Mech 3.0, 2000. Available from: <http://www.me.berkeley.edu/gri_mech/> 